\title{
The Development of Public Internal Financial Control in Albania - And His Role in Strengthening the Managerial Accountability
}

\author{
Dr. Hysen Muceku
}

hysen_muceku@hotmail.com

\author{
Doi:10.5901/ajis.2014.v3n4p301
}

\begin{abstract}
The concept of Public Internal Financial Control (PIFC) has been developed by the European Commission in order to provide a structured and operational model to assist national governments in reengineering their internal control environment and in particular to upgrade their public sector control systems in line with international standards and EU best practice. The democratic changes affecting all areas of life in the last years, have led to reforms in the management of public finances of the public sector in the Republic of Albania. On the road of the accession to the European Union, Albania is in the process of important conceptual, legislative and structural reform of the Public Internal Financial Control framework with the aim of strengthening the managerial accountability of the managers of public sector organizations and further develop independent internal audit. The paper aims to give some key issues regarding PIFC development in Albania such as: the level of transparency regarding the status of the financial management and control and internal audit in the public sector; the awareness of the Heads of public organizations about the importance of sound financial management and control and to enhance their managerial accountability; information about the self assessment of the heads of public sector organizations on the adequacy and the effectiveness of internal control and about the progress made. It also outlines the weaknesses, solutions and development opportunities based on the assessment of the status of the financial management and control systems as well as of the internal audit. Through conclusions it summarizes the main directions in which the Albanian institutions must be focused in the future for further development and improvement of management of public resources. The development of the new model of public internal financial control in Albania demands from all the participants in the process, leading to effective action in accordance with their roles and responsibilities. Only proper implementation of new legislation and efforts by all stakeholders can lead to achieving the goal - to create a modern system, reliable and functioning of public internal financial control. In this regard the CHU/FMC will outline specific measures related to strengthening managerial accountability and updating of legislation and methodology in the field of internal control in accordance with EU legislation and best practices. As one of the "three pillars" of the Public Internal Financial Control System, Internal Audit has developed and continuously improved in order to take its modern role as advisor for the assessment and systems and contributing to the achievement of strategic and operational objectives of the organization, always in accordance with international standards and best practices.
\end{abstract}

Keywords: Public Internal Financial Control (PIFC), Internal Audit, Financial Management and Control, Risk Management.

\section{Introduction}

PIFC (Public Internal Financial Control) System contains a comprehensive and consolidated control system, including the structure, method, administrative procedures and internal audit which is set to achieve management objectives based on principles of transparency, legality, efficiency and effectiveness PIFC system focuses on three main pillars:

- Sound financial management and control systems (FMC) as a primary responsibility of managers in each unit of public expenditure.

- Independent and objective function of Internal Audit (IA), to support management and to provide reasonable assurance that control systems are established in accordance with rules and standards, according to the principles of a sound financial management.

- Central Harmonization Units (CHU) in the Ministry of Finance (MF) - to design and implement a methodology, to harmonize and standardize the quality system for FMC and Internal Audit.

\section{Financial Management and Control}

The main actors of the current PIFC system in Albania are: the Minister of Finance, CHU/FMC (Central Harmonization Unit for Financial Management and Control) and CHU/IA (Central Harmonization Unit for Internal Audit). The Minister of Finance is responsible for establishing internal control systems to all public general government entities and fulfilling his 
duties in the field of FMC supported by the $\mathrm{CHU}$. The CHU/FMC is responsible for the implementation of public internal audit as the basis for monitoring and control of public finances. CHU/IA initiates and supports the process of creating a functionally independent internal audit service, in the ministries and at different levels of local government.

\subsection{Concept of Financial Management and Control (FMC)}

Financial Management and Control is a system of policies, procedures, activities and controls, which are established, maintained and regularly updated by the head of public unit and are put into practice by all the personnel aiming to address risks and to provide sufficient assurance that the objectives of the public unit are achieved through:

efficient, effective and economic activities;

compliance with the existing legislation and internal regulations and contracts;

reliable and complete operational financial information;

Safeguarding of information and assets.

\subsection{Assessment of FMC components in the Albanian public sector}

Financial Management and Control in the public sector is achieved through:

(i) creating an efficient and effective control environment, (ii) effective risk management, (iii) proper implementation of control activities, (iv) information and communication; (v) monitoring of the control activities of the public sector entities.

- The self assessment questionnaire on FMC components.

In order to collect information about the FMC status in the public sector, a self assessment questionnaire on FMC components for all public organizations - central and local government units was prepared and delivered.

The scope of the questionnaire was to address the level of fulfillment of the main requirements of internal control framework related to the five components of FMC - control environment, risk management, control activities, information and communication and monitoring. The self assessment control tool is intended to be used as well by the public sector entities in order to help them to identify the aspects of internal control in the respective organization where additional awareness and training needs to be targeted. The total number of the public sector organizations to which the self assessment questionnaire has been sent for reply is 435 (305 communes, 67 Municipalities, 12 Regional Councils, 50 Central Government units including line Ministries). Only 135 completed questionnaires have been received, which represents $31 \%$ of the whole organizations. However, most of central government units and big municipalities have replied. Most of local government units are represented by very small communes. Out of the Central government organizations completed questionnaires have been submitted by 12 ministries, 24 agencies and other relevant structures. Out of the local government organizations - municipalities, communes and regional councils - completed questionnaires have been submitted by 39 Municipalities, 12 Regional Councils and 48 communes.

Analysis of FMC self-assessment questionnaires:

\subsubsection{Control Environment}

The first group of components of internal control describes the basic conditions, completion of which is important for creating an appropriate control environment in a particular institution. The control environment provides our organization, by influencing the control consciousness of its people. It is up to the foundation where all other components of internal control structure as it raises and decides discipline. The control environment is the key to good management of public funds and other elements of financial management and control. The section of control environment in self-evaluation questionnaire contains 31 questions, divided in five subsections, and respectively: setting goals, personal and professional ethics, and the management style of work, organizational structure, human resources policies and procedures.

\subsubsection{Objectives Setting}

General estimates indicate that most public institutions have designed the mission, and strategies that have been distributed to all staff or at least to the management level of the unit. More detailed results shows that there are about $36 \%$ of institutions that do not have the mission statement or the strategy for determining the priorities of the institution. This phenomenon is verified in the local government units, especially in small communes. Central institutions and a large 
part of the municipalities, which cover about $51 \%$ of institutions, have responded to the mission statement, have adopted strategies and action plan for achievement of their goals in accordance with the requirements of Law no.9936, "On management of budgetary system in the Republic of Albania". The following chart reflects some statistics about mission design, strategy, action plan in public institutions and distribution of them to all employees.

Conclusions and recommendations: Considering that for this component have a number of institutions which have a negative response, the primary objective remains that the requirements of the 9936 Law "On budget management system in the Republic of Albania" to lie to be applied in all local government units. All local government units must have their parts of the program budget medium-term budget in accordance with procedures approved by the Minister of Finance as well as ongoing monitoring of their implementation.

\subsubsection{Personal and Professional Ethics}

With regard to personal and professional ethics, the managers have stated positive results in implementing the existing legal framework with regard to ethics. During the analysis of responses to questionnaires, we may conclude that the legal framework in force is know and applied from most of public entities. The legal framework is represented by the: Law no.152/2013 "For the Civil Servant" and Law no. 9131, dated 09.08.2003 "On the Rules of Ethics in Public Administration". A part of the institutions, mainly the central ones, have made progress by drafting their own code of ethics, or include ethics elements in their internal regulation document. Despite the large number of institutions that claim they apply the Code of Ethics, or special rules of ethics included in their institutional regulations, in $58 \%$ of institutions there is no promotion procedures and updating knowledge of staff with these rules. It also displayed a pronounced weakness in terms of reporting violations. It is responsibility of managers of institutions to determine the development and implementation of procedures for reporting violations of ethics rules. Regarding the existence of procedures for reporting errors, fraud and irregularities - 53\% of institutions state that currently do not have such existing procedures, but planning their presentation;

\subsubsection{Managerial style of work}

With regard to management style of work, there is a positive element of best practice, the held of regular management level meetings to discuss about main issues of the organization. In some institutions, the frequency and manner of organization of the meetings are described in internal regulations of the institutions. One of the elements essential components of managerial style is the delegation of tasks. Currently noted shortcomings in this regard, especially in nonexistence of written procedures for delegation of duties and description of the way the powers could be delegated. Institutions declare that the delegation of duties is realized in practice, but this element is not reflected in job descriptions.

\subsubsection{Organizational Structure}

With regard to the organizational structure, managers consider that in their organizations there is good organizational structure, and there are job description for employees approved and updated on regularly annual basis. Requirements of Law no.9936, "On management of budgetary system in the Republic of Albania", regarding the appointment of Authorizing and Executing officers result as fulfilled by the majority of authorities (90\%). However, we noted that in practice this functions are not always covered by the high level managers and their direct subordinates. Leadership interaction between institutions and internal audit results effective. Only 5\% of institutions have provided negative response in these indicators and this percentage is represented mainly by communes.

\subsubsection{Human resources management policies and procedures}

There are good results in terms of existence of job description and review of the same in central government and large municipalities. Regarding local government, and specifically in the communes, most of them replied that there does not exist job description in written form. Despite legal framework requirements for preparation of job description for each position, still these requirements are not applied. The results show that in terms of the control environment, managers are confident they have created good conditions for the basic functioning of the institutions they manage. 


\subsubsection{Conclusions and recommendations}

The focus for increasing the effectiveness should be in determining the mission, strategy and objectives, and in designing specific action plans which should include deadlines and responsible

persons for their implementation. Must be reviewed the assignment of the positions of executing officers. With the new draft financial management and control law, it is intended to clarify the roles and responsibilities of the key actors of the system.

\subsubsection{Risk Management}

Risk management is the process of identifying, evaluating and monitoring the risks facing the organization in achieving its objectives and performance of controls necessary to keep exposure to risk at a level acceptable to the institution. This section of the self-evaluation questionnaire contains a few questions (four in total) since it is considered that risk management is a new concept for our public administration. In this context, more than $50 \%$ of institutions state that they do not possess any procedure regarding identification, analysis and control of risks that impede the achievement of the goals of the institution, specifically during mid-term budget planning. But while there is no written procedures for identifying risks, they are subject to continuous discussion and evaluation between the stakeholders and employees in order to minimize risks and make possible the achievement of the objectives. The results shows that $67 \%$ have responded very good, $24 \%$ good, and only $9 \%$ replied that do not assess risk or take measures for its mitigation.

Conclusions and recommendations: Some positive side in this regard, as the existence of a good practical discussion on the possible risks during the process of setting objectives are noted. However, based on comments received from institutions, conclude that even in cases where there are risk management procedures, they focus more on financial risks and not in all kinds of risks that could prejudice the achievement of goals.

\subsubsection{Control Activities}

Control activities are the rules, procedures and actions aimed at reducing the risks with a view to achieve the objectives of the organization and promote the implementation of decisions of the head of the entity. The results of the self assessment questionnaires replies, define this element of financial management and control rated as very good in many institutions, central and local ones. The heads of state institutions that have met the minimum legal requirements and have put in place appropriate controls in the following areas: the existence of rules/guidelines for the description of internal key operational and financial processes, including documents and information flow, decision-making, setting the activities of internal controls, the double signature system, safeguarding assets and segregation of duties, documentation of all operations, activities and financial transactions. As highlighted weaknesses of the system, results in the lack of support of information systems technology and above all in the local government units. With regard to training needs, over $87 \%$ of institutions have expressed their need for training for managers and specialists, in the field of financial management and control. It is the responsibility of $\mathrm{CHU} / \mathrm{FMC}$ to identify needs and develop an appropriate training strategy for public sector employees.

Conclusions and recommendations: The emphasis and focus in the future should be the development of IT systems to improve control activities. Also, each unit must have internal regulations which should summarize the description of all procedures for the activities conducted, provide access to information and assets from the right people, developing IT systems to support control activities.

\subsubsection{Information and Communication}

The fourth group of components of internal control issues related to information and communication.

Information is the basis of communication required for effective performance of assigned duties.

Information and communication system must provide identification, collection and distribution of the information in the appropriate form and terms in order to allow the performing of duties. From the graphical presentation of answers to questions in this component of FMC, is found that over $28 \%$ of institutions have no written guidelines regarding the mode of communication within the institution, $18 \%$ of these institutions have a good level and $54 \%$ of institutions have internal regulations including communication rules (this mainly in the central institutions, regional councils and large municipalities). 
More than $48 \%$ of institutions declare that their IT system is not developed in those levels to support the monitoring of targets. The central institutions and precisely $43 \%$ of them, have answered "very good", $27 \%$ good and $29 \%$ poor. Feels towards the establishment of procedures necessary to provide real information, for appropriate, timely implementation of some activities within the institution. This need is evidenced in more than $75 \%$ of responses to questionnaires.

Conclusions and recommendations: The responses show that, public sector institutions has not yet a adequate system of communication and information. This prevents the daily work of staff and managerial decision making. It also creates complications in the achievement of the objectives of institutions (known as the weakness in the "control environment"). In this regard is noted that in some central institutions, especially those created recently, they created several electronic databases and some others are in process, in order to provide better information.

\subsubsection{Monitoring}

Monitoring is the process of reviewing the entire activity of the organization, which aims to provide reasonable assurance that control activities operate according to the purpose for which they were created and remain efficient with the passage of time. As a strong point of this component results the line of reporting; its regularity is a good practice. About $88 \%$ of managers consider that the progress towards achieving goals is regularly monitored and the reasons that may impede their fulfillment are analyzed. Following the line of interaction with auditors, there is a high percentage of institutions (70\%), which states that they respond appropriately to internal audit recommendations.

\subsection{Findings}

Conclusions and recommendations: A good part of the management state that they review financial management and control not only on an annual basis. Some of them are involved in the regulation of their internal performance indicators, monitoring tools and regularity in reporting. However, establishing a new legal framework for FMC, will create strong basis for improvement of this component.

\subsubsection{Positive Aspects}

The existence of a sound control environment in a good part of its components elements.

The requirements of Law no.9936 "On management of budgetary system in the Republic of Albania" are met, especially regarding the drafting of mission, strategies and objectives. Generally in all public organizations results that, structures are suitable for the dimensions and character of the organization activity.

The existence of job description and review, mainly for managerial positions in all central and local government institutions.

Has been appointed in almost all public entities the Authorizing officers and executing officers in

accordance to the requirements of Budget law.

Dominant part of heads of public entities testify the proper functioning of lines of reporting; regular managementlevel meetings to discuss crucial issues for organization management.

\subsubsection{Identified gaps}

- Lack of analysis, documentation and management of risks that impede the achievement of the objectives in public organizations.

- Lack of awareness at the right level of managers and staff to the concepts of financial management and control.

- Lack of codes / rules of ethics for every organization. Lack of practices and written rules for signaling irregularities.

- Delegation of duties turns out to be good practice but not regulated by normative acts, or included in job descriptions.

- It is required to intensify training for heads of entities in order to improve the use information. Managerial supervision focuses mainly on financial aspects than on monitoring objectives or efficiency.

- Communication within the unit is not uniform, and the staff is not always aware of the product/ 
- outcome of the processes in which they contribute.

\subsection{Objectives for the future}

- The following directions need to be addressed in the future:

- Strengthening managerial accountability and changing the mentality of the managers

- responsibility to see top-down, by consolidating the legal basis and awareness seminars.

- Improve and increase the financial management methodology and control, including development of: Guidelines for the development of risk management, asset management, guidelines for the preparation of a statement of quality and report son FMC existing system,

- Identify the needs for training and support to training institutions and professional conduct in the field of financial management and control of senior officials and managers of public sector institutions;

- Strengthening the capacity of CHU/FMC staff through training and on-job training, Increase awareness regarding new FMC concepts in central and local administration.

\section{Internal Audit (IA)}

\subsection{Sources of information on IA activities in the public sector}

Information about the internal audit activity in the public sector is collected on the basis of audit reports and annual audit reports for 2012, 2013 received from IA units. This information has been received from 13 central institutions, five subordinate institutions, four Independent Institutions and part of the audit of Local Government structures. Likewise, a supplementary form titled "Questionnaire for annual tests" was delivered to IA representatives of IA structures in the public sector, and the 40 replies received served as source of information for this paper.

\subsection{Establishment of IA functions in the public sector}

\subsubsection{Establishment of new IA Units}

Internal audit function should be implemented by all public sector institutions as requirement of Article 2 of Law no.9720 "On Internal Audit in Public Sector (including all central and local government institutions, other institutions, central and local which provide public services and, independent institutions). Audit Procedures Manual further defines the criteria for job creation and operation of the internal audit structures and it highlights the fundamental principles on which this activity is exercised.

Implementing the above framework, by the end of 2012, 125 units were created (internal audit structures), which exert their function at the level of central government (in all line ministries except the Ministry of Integration), subordinate institutions, local levels (municipalities and communes), and independent institutions. In 2012 the number of structures of central government audit units was 74, compared with 57 existing in 2011; this represents an increase of $32 \%$. In the case of local government, the increase was of $28 \%$. This rising trend is a positive indicator for the development of auditing systems, which show a greater expansion of practical implementation of the Law on Internal Audit. Despite improvements made in this direction, there are still issues that have a significant impact on creation and implementation of institutional capacity of internal audit. The CHU/IA in his role as leader and coordinator of all activities of the internal audit system, determines that these issues continue to be vulnerable. The most important issue is related to the fact that high level management in public entities did not understand properly the role of internal audit and its mission. Thus in many subjects has not yet established the internal audit unit. Also, some entities do not respect the criteria of establishing audit structures. Within the IA units established the principle of independent function, but there are frequent occasions when these units are required to act as control structures, thus exercising the function of financial inspection. Currently there is no clear division between the role of functionally independent internal audit and financial inspection, as one of the basic requirements of European standards in the field of auditing. With regard to the respect of deadlines for the establishment of internal audit units, the most significant weaknesses are in the area of local government units. 


\subsubsection{Administrative capacity of IA units.}

Another important element in the progress of audit activity, in addition to creating the structures, is meeting the needs of human resources with integrity and professional competence. Because of the very delicate nature of the internal audit profession, which includes not only evaluation of control systems (financial or other), but also provides recommendations, the auditors should possess and demonstrate in the context of their activities, appropriate professional knowledge and integrity to ensure proper presentation of the effectiveness of the audit tasks. By analyzing the completeness and composition of the audit structure, we note that by the end of 2012, from 416 positions for internal auditors (based on organizational schemes adopted), has been hired 406 auditors, of whom 277 certified auditors, 58 in the process certification and 71 still not certified. In 2012, among 119 Audit structures, 106 of them are completed of staff. According to the data, progress is made in recruiting internal auditors in the past two years. In 2012 the number of employees rose by $34.4 \%$ against 2011.

In addition during 2012 the number of IA Units was increased with 11\% achieving 136 IAU in total. CHU/IA continues to implement the training program "Certification of Internal Auditors in Public Sector" to four relevant curricula and modules: Audit, Governance and Control, Accounting and Legislation. Organization, management and development of training for certification "Internal Audit in Public Sector" are a direct product of collaboration between CHU/IA and Training Commission, as the bodies responsible for this process.

\subsection{Evaluation of performance and reporting of internal audit units}

The Audit Units mainly consider the following as areas with the greatest risk:

- Financial management systems,

- Dependent entities which have responsibility for significant amounts of public funds coming from several financial sources:

- Strategic Investment projects working;

- Subjects or areas that have significant weaknesses in internal control systems;

- Human Resource Management;

- Units and areas with low levels of knowledge and use of information technology systems.

Based on the assessment of areas with higher risk mentioned above, audit units have set their priorities. The main sources are committed to audit units or high-risk areas, with allocation of sufficient time and technical expertise and other resources to the needs identified. However, it was conducted additional missions at the request of management audit, as a result of updating the risk assessment during the year and in cases where the management sees fit such a mission. When assessing the risk level was high, was appointed and length suitable for tracking recommendations. In this way, internal audit is not only intended to find the conditions, consequences and responsibilities, but above all, improvements and prevent repetition of such phenomena in the future.

- Generally, the total number of audits planned and implemented also has increased year by year, and this indicator can be seen that if combined with other factors (cost/benefit), shows a process for improving increase the effectiveness of audit work. However, given the observed deviations in fact opposed the plan, as well as trends over the years concludes that they are almost the same factors influence that consists of:

- Changing the priorities in the activities of the entities audited;

- IA missions overlap with audits conducted by other audit institutions, especially the SAI (Supreme Audit Institution);

- Interference management in implementing audit plans seeking audits,

- Lack of capacity to audit and frequent change of audit staff and sometimes the heads of IAU;

- Performance of the auditor's disappointing, especially the staff employed recently.

\subsection{Audit findings and recommendations}

Specifically for internal audit structures in prefectures, it is considered as fundamental problem the collisions between the specific functions provided in the law "On the Institution of the Prefect" regarding financial control and, internal audit functions according to the IA Law. One of the most important issues relates to typology of audit engagements. Currently, the Internal Audit Law in force, does not have a clear distinction between audit and consulting services and insurance, respectively, providing the kinds of commitments are not listed. 
- The overall assessment for internal audit activities is positive, as significant improvements in the country, but at the same time, some important factors have a negative impact on achieving the objectives of the audit and should be handled properly so to improve future results. In general, the same gaps are found in almost all supervised entities to which summarize as follows:

- The quality of preparation of materials is estimated to be at the level required by standards. Reports are incomplete and rarely heard work of the unit itself.

- There is sufficient knowledge for the presentation and setting up controls as part of the activities of the organization. Thus, auditors have difficulty in evaluating internal control. When evaluation of control provided, it is usually theoretical, without any of the concrete process of auditing and assessment of inherent meaning and control risks.

- Lack of clarity on these facts limit the role of the auditor; he/she acts just like the facts and the register fails to provide useful recommendations to improve systems in terms of preventing adverse events, and in enhancing the effectiveness, efficiency and economics of the process that is audited.

- Frequent deviations from plans, audits required by management to increase the risk of impact functional independence of the auditor, expressed exactly the independent planning, execution as well as impartial, objective assessment of audit evidence and provide an independent opinion. Besides the unsatisfactory level of preparation of reports, there are many gaps in the procedure for communicating the audit results with management. The status of some structures remains unresolved audit. There are still facilities that operate within the internal audit, but they are called, respectively, control units and perform the duties of inspection.

\subsection{Further developments regarding IA in the future relate to:}

Low levels of knowledge of the management of new and modern role of internal audit within the

PIFC system recently has been an obstacle to the proper functioning of the Internal Audit in the public sector.

- Improving the awareness of managers regarding PIFC, FMC and IA.

- The low level of awareness is the issue of non-compliance of the basic principle of functional and organizational independence of internal audit.

- Specific activities should be undertaken in order to create an environment full legal and procedural training to conduct the internal audit function.

- Building administrative capacity of the units that IA and quality of internal audit remains to be done in terms of professional training and capacity of auditors.

- Guarantee stability of the professional staff is an issue that is often found in structures, especially the audit of public entities or other levels of local government. Changes unfounded trained staff brings not only loss of the acquired professional experience, but they also have an impact on the quality of audits.

Create and implement a specialized program for the purchase of practical skills will contribute to increase the quality of internal audit structures

\section{Conclusions}

The development of the new model of public internal financial control in Albania demands from all the participants in the process, leading to effective action in accordance with their roles and responsibilities.

Only proper implementation of new legislation and efforts by all stakeholders can lead to achieving the goal - to create a modern system, reliable and functioning of public internal financial control.

Specific measures related to strengthening managerial accountability and updating of legislation and methodology in the field of internal control in accordance with EU legislation and best practices should be outlined.

As one of the "three pillars" of the of Public Internal Financial Control System, Internal Audit has developed and continuously improved in order to win its modern role as advisor for the assessment and systems and contributing to the achievement of strategic and operational objectives of the organization, always in accordance with international standards and best practices.

In this context, responsibility to develop and implement all measures necessary for the successful implementation of the PIFC model and achievement of high professional standards in the field of internal auditing in the public sector remains the most important issue to be addressed during the future developments in Albania. 


\section{References}

Decision of Council of Ministers "On approval of PIFC Policy Paper and Action Plan".

Law No.9936, date 26.6.2008 "On Management of Budget System in Albania".

Law No.10 296, date 8.7.2010 "On Financial Management and Control in Albania".

Law no.9720 date 23.04.2007 "On Internal Audit in Public Sector in Albania".

"The Internal Auditing" Handbook, 2005, K H Spencer Pickett

"Internal Control", funded by USAID 2009.

"The role of Auditing in Public Sector Governance", IIA, Professional guidance.

The Institute of Internal Auditors "The role of internal auditing in public sector governance", Professional guidance, November 2006.

"Promoting good governance" NAO, Bob Pirdeaux and Mary Radford.

"The orange Book- Management of Risks- Principles and Concept" HM Treasury.

The report's of PIFC in Albania for year's 2011 and 2012.

"Internal Audit Quality Review Processes", The Albanian Ministry of Finance. 
